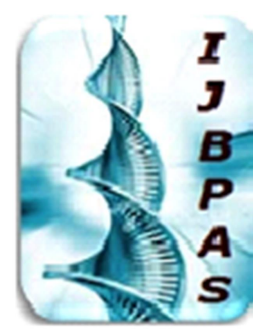

International Journal of Biology, Pharmacy and Allied Seiences (IJBPAS) 'A Bridge Betusen caboratory and QReado'

Www.jibpas.com

\title{
GENERALIZED LINEAR MODEL APPROACH FOR ROAD ACCIDENT PATTERNS IN KERALA, INDIA
}

\section{BHAT PR ${ }^{1 *}$, STAVELIN ABHINANDITHE $\mathrm{K}^{2}$, MADHU ${ }^{3}$ AND SAHANA KS $^{4}$}

1: Faculty of Life Sciences, Department of Water \& Health, JSSAHER, Mysore, Karnataka, India 2: Assistant Professor, Division of Medical Statistics, Faculty of Life Sciences, JSSAHER, Mysore, Karnataka, India

3: Associate Professor, Community Medicine, JSS Medical College, JSSAHER, Mysore, Karnataka, India

4: Faculty of Life Sciences, department of Water \& Health, JSSAHER, Mysore, Karnataka, India

*Corresponding Author: Preethi R Bhat: E Mail: preethirpn10@gmail.com

Received $20^{\text {th }}$ Feb. 2021; Revised $20^{\text {th }}$ Mar. 2021; Accepted $16^{\text {th }}$ April 2021; Available online $1^{\text {st }}$ Dec. 2021

https://doi.org/10.31032/IJBPAS/2021/10.12.5768

\section{ABSTRACT}

India's development over the past few years and an individual's desire to own vehicles has led to increased motorization across different states in India, with Kerala being one among them. In today's competitive world, everyone is in hurry and their impatience has resulted in careless attitudes towards driving, as well as towards vehicle maintenance, which in turn has risen the number of fatalities due to road accidents in Kerala. In this study we have made an effort to determine regions that are at greater risk of fatality and the vehicles that most prominently contribute to such risk using the Generalized Linear Model (GLM) approach. On comparison, Negative Binomial Regression Model (NBRM) showed up to be more appropriate over Poisson Regression Model (PRM). With Wayanadu as the baseline district, Idukki reported the lowest (1.303) incident rate. Among Ernakulam, Kozhikkode and Trivandrum, urban areas were exposed to lower fatality risk as compared to rural areas. Further, 'KSRTC bus', 'Cars \& Two-wheelers' were found to cause more fatal accidents with $0.1 \%$ and $0.001 \%$ increase in deaths for an increment of one case due to each of them respectively. The prediction model adopted, thus yielded convincing results, which can be utilized for improving not only the human but economic and environmental conditions in Kerala.

Keywords: Generalized Linear Model, Negative Binomial Regression Model, Poisson

Regression Model, road accidents 


\section{INTRODUCTION}

Accidental deaths on Indian roads have risen alarmingly over the years involving more than 9-fold, from 14,500 in 1970 to 137,400 in 2013 with urban areas suffering less deaths (36.6\%) as compared to rural areas $(63.4 \%)$ in 2011 . While fatality rates, have declined over the years from 87.5 in 1970 to 8.6 in 2013 , they are still very high compared with developed countries. If no required steps are taken then road accidents in India by 2025 may exceed 0.25 million $[1,2]$. Accidents are a dynamic multiple cause phenomenon. The analytical factors are categorized into environment and human related factors. The mixed Kerala's topography includes a hot and wet coastal plain rising slowly up to the Western Ghats' high hills and mountains. Currently, increasing population, urbanization, enormous growth of motor equipped as well as non-motorized and para-transit vehicles, the lonely supremacy of the road transport sector over other modes catalyze a number of accidents in Kerala. Of the 15,525 fatal accidents in 2010-2013, 76 percent of the accidents involved a human factor with $20 \%$ involving a path factor and only 4 percent involved a factor in automobiles. Heavy vehicles, i.e. Trucks and Buses, were involved in 32 per cent of all fatal incidents, cars / taxi / tempo involving 20 per cent with the highest involvement of two-wheelers [3]. In 2015-
16, there were 1330 ( 4 per day) and 3303 (9 per day) accidents due to KSRTC bus against 5686 and due to private bus against 25449 buses respectively. As of March 2017, Kerala has 110.3 lakh motor vehicles registered with 330 vehicles per 1000 population, experiencing a compounded annual growth rate greater than ten percent over past two decades. Bike accidents accounted for $38 \%$ and motor cars for $28 \%$ of the total registered accidents in the state approximately in the same year [4]. Road traffic collisions and injuries are largely preventable as the likelihood of accident injury is relatively predictable and there are several assisting measures that have been shown to be successful. The most successful way of minimizing deaths and injuries will be through an integrated strategy that requires close cooperation between several sectors. Progress is being made in other areas of the world where ambitious multisectoral policies contribute to gradual reductions in the number of traffic deaths and accidents on the path. These approaches focus on four main factors that lead to the likelihood of a road accident - exposure, attitudinal factors, road conditions and vehicle components [2].

The main objective of this study is to determine the effect severity of geographic and vehicle types on fatal accidents and 
thus address the possible underlying reasons by using the appropriate Generalized Linear Model (GLM) that best matches Kerala State's 11-years data from 2007-2017. GLM is a special class of nonlinear models where it is assumed that the dependent variable, here the accidental deaths, is a part of the exponential family which encompasses numerous distributions, especially non-normal discrete distributions including Bernoulli, Binomial, and Poisson which can deal with binary and count data. In this retrospective data analysis we come across the two most common models that can be employed comprising of both numerical (automobile types) and categorical (Kerala districts) variables. One being, Poisson Regression Model (PRM) for handling equidispersion data and the other, Negative Binomial Regression Model (NBRM), which is a generalization of Poisson regression and provides flexibility over the restrictive assumption that the variance is equal to the Poisson model mean $[5,6]$.

\section{MATERIALS AND METHODS}

\subsection{Study area}

The total area of Kerala state, $38,863 \mathrm{~km}^{2}$, is split into fourteen districts which are categorized as North, Central and South Kerala with the entire state population being $33,387,677$ as of 2011 . Roads cover 1,524 $\mathrm{km}$ of National Highways $(\mathrm{NH})$, State Highways (SH) and district roads cover $1,525 \mathrm{~km}, 4341.6 \mathrm{~km}$ and 18,900 km of the roads respectively. Also, an area of $15,577 \mathrm{~km}^{2}$ of the state belongs to the forest region [7].

\subsection{Data collection}

2007 to 2017 accidental data, showing regional distribution of fatalities along with the cases due to different types of vehicles and causes were freely available in keralapolice.gov.in, official website of the Kerala police department.

\subsection{Generalised Linear Models}

Once we begin modelling count data, it is necessary to test the data to see if there are any significant assumption violation on which the fundamental Poisson model is constructed. Any other count model can be considered as its deviation or modification. In addition to the accidental deaths being counts following Poisson distribution with identical mean and variance, they are expected to be non-negative occurring independently and Pearson chi square dispersion statistic nearing to the value 1 , indicating that observed and predicted variation in the death occurrence are the same. . In addition to this, the data should also be checked for excess multicollinearity arising due to high correlation (Pearson correlation coefficient, $|r| \geq 0.9)$ between some of the explanatory variables $[\mathbf{8}, \mathbf{9}]$.

\subsubsection{Poisson Regression Model}

In this model, death incidence rate, $\mu$ is calculated by a set of predictor variables $k$ 
(the X's), which involves the different types of vehicle cases as the discrete variables and districts representing the various categories. The related quantities can be expressed as,

$$
\mu=\operatorname{texp}\left(\beta_{0} X_{0}+\beta_{1} X_{1}+\ldots \ldots . .+\beta_{\mathrm{k}} X_{\mathrm{k}}\right)
$$

$\beta_{0}$ is the intercept and $X_{0}=1$. The coefficients of regression, $\beta_{0}, \beta_{1}, \beta_{2} \ldots \beta_{\mathrm{k}}$ are the parameters not known and hence has to be determined from the provided dataset. Accordingly, the basic PRM for death counts (y) reported when the population is exposed to time $t$ in years can be described as

$$
\operatorname{Pr}\left(\mathrm{Y}_{\mathrm{i}}=\mathrm{y}_{\mathrm{i}} \mid \mu_{\mathrm{i}}, \mathrm{t}_{\mathrm{i}}\right)=\frac{e^{-\mu_{i} t_{i}}\left(\mu_{i} t_{i}\right)^{y_{i}}}{y_{i} !}
$$

where, $\quad \mu_{\mathrm{i}}=\mathrm{t}_{\mathrm{i}} \mu\left(\mathrm{X}_{\mathrm{i}}^{\prime} \beta\right)$

$$
=\mathrm{t}_{\mathrm{i}} \exp \left(\beta_{0} \mathrm{X}_{0 \mathrm{i}}+\beta_{1} \mathrm{X}_{1 \mathrm{i}}+\ldots \ldots . .+\beta_{\mathrm{k}} \mathrm{X}_{\mathrm{ki}}\right)
$$

(Yang and Berdine, 2015)

\subsubsection{Negative Binomial Regression}

\section{Model}

For the death counts following negative binomial distribution, Poisson Regression technique can be extended such that it allows the process variance to surpass the mean. The Negative Binomial Model is derived from the Poisson model by,

$$
\ln \lambda_{\mathrm{i}}=\mathrm{X}_{\mathrm{i}} \beta+\varepsilon_{\mathrm{i}}
$$

where $\lambda_{i}$ is the mean number of deaths occurring in the ith district; $\beta$ is the vector representing the parameters to be estimated; $\mathrm{X}_{\mathrm{i}}$ is the vector representing ith geographic and corresponding cases due to 8 different automobile categories as the explanatory variables along with the value of $\mathrm{X}$ when for the intercept. $\varepsilon_{\mathrm{i}}$ is the error term where $\exp (\varepsilon)$ having 1 as the mean and $\alpha 2$ as the variance belongs to gamma distribution. The consequent probability distribution can be given as,

$$
\operatorname{Prob}\left(n_{i} \mid \varepsilon\right)=\frac{\exp \left[-\lambda_{i} \exp (\varepsilon)\right] \lambda_{i}^{n_{i}}}{n_{i} !}
$$

where $n_{i}$ is the number of fatalities for particular districts over time period t. The integration of $\varepsilon$ from this expression results in the unconditional distribution of $n_{i}$. This distribution is formulated in

$$
\operatorname{Prob}\left(n_{i}\right)=\frac{\Gamma\left(\theta+n_{i}\right)}{\left(\Gamma(\theta) n_{i} !\right)} u_{i}^{\theta}\left(1-u_{i}\right)^{n_{i}}
$$

where $u_{i}=\theta /\left(\theta+\lambda_{i}\right)$ and $\theta=1 / \alpha ; \theta$ and $\alpha$ being the scale and dispersion parameter respectively.

Estimation of the NBRM can be done by using conventional maximum likelihood methods. The function in correspondence to this is,

$$
\mathrm{L}\left(\lambda_{\mathrm{i}}\right)=\prod_{i=1}^{N} \frac{\Gamma\left(\theta+n_{i}\right)}{\Gamma(\theta) n_{i} !} u_{i}^{\theta}\left(1-u_{i}\right)^{n_{i}}
$$

where $\mathrm{N}$ represents the total number of districts. Maximizing the above function, estimates for the $\beta$ and $\alpha$ coefficients can be obtained. There is an ancillary parameter in 
this model, in comparison to the Poisson model, so that,

$$
\operatorname{Var}\left[n_{i}\right]=\mathrm{E}\left[n_{i}\right]\left\{1+\alpha \mathrm{E}\left[n_{i}\right]\right\}
$$

The choice between the two models can be understood clearly by using the estimated coefficient, $\alpha$, and the Goodness of fit test. A $\alpha$ value of 0 or very close to it condenses the Negative Binomial Model to Poisson $[9,11-13]$.

\section{Wald Chi-squared test}

The Wald test known as the Wald ChiSquared Test is an approach to figure out if the regressors in a model are meaningful, implying addition of something to the model. Variables that make no difference can be removed without creating significant affect to the model. The Wald test is generally told in terms of chi-squared, as we are aware of the distribution of samples (as $\mathrm{n}$ tends to infinity) The Wald statistic can be expressed as, [14].

$$
\mathrm{W}_{\mathrm{T}}=\frac{\left[\widehat{\theta}-\theta_{0}\right]^{2}}{1 / I_{n}(\widehat{\theta})}=I_{n}(\hat{\theta})\left[\hat{\theta}-\theta_{0}\right]^{2}
$$

where $\hat{\theta}$ being the Maximum Likelihood Estimator and $I_{n}(\hat{\theta})$, the expected Fisher information.

\section{Goodness of fit}

Among a family of models under competition, with different parameter quantities, Akaike's Information Criterion (AIC) and Bayesian Information Criterion (BIC) helps to recognize the model with the most resemblance. AIC and BIC can be defined as follows:

$$
\begin{gathered}
\mathrm{AIC}=-2 * \mathrm{ML}+2 * \mathrm{k} \\
\ldots \ldots .(9) \\
\mathrm{BIC}=-2 \mathrm{~L}+\mathrm{kln}(\mathrm{n}) \\
\ldots \ldots .(10)
\end{gathered}
$$

with ML representing the maximum $\mathrm{L}(\beta)$ and $\mathrm{k}$ is the number of the model variables, and $\mathrm{n}$ is the model observations. The model with the smaller values of AIC and BIC can be considered the better fit one.

The deviance value 2(LL ( $\beta)$-LL (0)) which follows a chi-square distribution was used to calculate the overall goodness-of-fit statistics. The log-likelihood ratio of the model described as $\left.\rho^{2}=1-\operatorname{LL}(\beta) / \operatorname{LL}(0)\right)$, is an indicator of the additional variance in accident deaths explained by the model obtained to the constant term $[\mathbf{9}, \mathbf{1 5}]$.

\subsection{Statistical methods}

The statistical softwares, Excel 2013 and SPSS Statistics 22 (IBM corp.) served useful in the application of the multivariate techniques adopted in this study to determine the best prediction model. Level of significance was set to 0.05 .

\section{RESULTS}

\subsection{Descriptive analysis}

There is a clear rise and fall in both the number of cases and deaths over the eleven years. Even though highest number of cases (39917) were recorded in the year 2007, deaths were found to maximum (4287) in 
the year 2016. This makes it clear that, accidents have shown a dreadful impact on the public which requires an immediate remedy (Figure 1).

From the Table 1 observations we can say that cases due to cars and two wheelers have shown an overall increase from one year to the next year with the total reported cases during the interval being 113833 and 289684 respectively. Further, comparatively, accident occurrences were very high due to these two vehicles. However, remaining vehicles exhibited ups and downs in their distributions. In addition to this, on comparison, incidences due to unknown vehicles and Kbus were found to be minimum.

Each district faced adverse suffering mainly due to the driver's attitude toward driving with Eranakulam, Trivandrum and Trissur being the most effected while least effecting Wayanadu and Kasarakodu regions.

\subsection{Poisson and Negative Binomial}

\section{Regression analysis}

\subsubsection{Assumption testing}

The endogenous variable considered for the study (deaths) is certainly discrete nonnegative counts having independent occurrence. In order to remove extreme multicollinearity, resulting due to highly correlated variables $(|r| \geq 0.9)$ and to obtain more accurate meaningful results, we combined car and two wheeler cases together ('Cars \& Two-wheelers') as well as incidences due to jeep and others ('Others') (Table 3).

Tests conducted to check whether the death occurrences follow normal or Poisson distribution, yielded highly significant $\mathrm{p}$ values $(<0.05)$, which is an indication that neither of the distributions best fit the data. Further, greater value of variance than the mean, is in implication that NBRM is the more appropriate model. Also, this becomes more evident once we look into the goodness of fit statistics comparing the two models, given in Table 4 .

The high significance $(p$-value $<0.005)$ of omnibus test for both the models states that inclusion of predictors provides more efficient results than the one involving only intercept. The ancillary parameter value approaching 0 for the Negative Binomial Regression Model (0.0045), creates a confusion as to which model to choose, which can be cleared comparing the other model statistics. According to the aforementioned criteria, as compared to the PRM, NBRM has lower AIC and BIC values with deviance statistic approaching 1 (0.915), whereas for Poisson model the value exceeds 1. Therefore we can conclude that Negative Binomial model is comparatively best fit to the dataset providing predicted death counts close to the observed ones and we continue to work with the model to obtain further results. 


\subsubsection{Estimation and Prediction}

The p-value obtained from the Wald's chi square test is highly significant (pvalue $<0.05$ ) for all the Kerala districts. The Negative Binomial Model considers one of them as the reference category with respect to which all the other regions can be compared. B column provides the parameter coefficients which can be explained as the decrease or increase of the expected log of deaths in a particular region with comparison to the baseline district (here, Wayanadu with $\mathrm{B}=0$ and $\operatorname{Exp}(\mathrm{B})=$ 1) depending on whether they take negative or positive values. Exp (B) also called the exponentiated regression coefficient gives the incident rate ratio (IRR), defined as the ratio of incident rate (IR) of the given place to that of Wayanadu. We mainly focus on IRR to interpret our results. We can clearly observe that incident rates of every district is corresponding Exp (B) times greater than that of the reference region with other variables held constant. Idukki was found to be having the lowest rate of death incidence, that is, 1.303 times more than Wayanadu's IR respectively. Moreover, rural areas of Ernakulam, Kozhikkode and Trivandrum were at substantial risks than their urban areas. Among the covariates, Wald's test showed significance only for accident cases due to KSRTC bus (p-value $=0.008)$ and 'Cars\&Two-wheelers' ( $\mathrm{p}$ value $=0.000$ ), which is an evidence that they are the considerable contributors of death prediction in each Kerala district whereas the left over vehicle types were found to be insignificant ( $p$-value $\geq 0.05$ ) predictors. Further, with every unit increase in 'Kbus' and 'Cars\&Two-wheelers' cases, expected log count of people dying increases by 0.001 and 0.0001 every year respectively. In other words, we can say that as the Kbus instances rises by 1, the death occurrences for the given year rises by $0.1 \%\left[(1.001-1)^{*} 100\right]$ of the total deaths occurred in the previous year. Similarly, a single increment of accident incidence due to cars and two wheelers kills about an extra $0.01 \% \quad[(1.0001-$ 1)*100] people. All the parameter coefficients had low standard error values and their exponentiated values lay within the $95 \%$ confidence interval (Table 5).

On the basis of the above parameter estimation results, NBRM estimates the average deaths occurring in each district for the values of all the covariates fixed by the model given by, Kbus $=75$, Pbus $=223$, Lorry $=132$, Mini $=116$, Auto $=394$, Cars\&Two-wheelers $=2158$, Others $=169$, Unknown $=20$. The mean values are displayed in the Table 6. The predicted model equation for the first district (Alappuzha) is given by

$\lambda_{1}=\exp (4.045+1.318+$ Kbus $* 0.001+$ Pbus * $0.0001+$ Lorry * $0.0001+$ Mini * $0.0001+$ Auto $* 0.0001+$ Cars\&Two- 
wheelers $* 0.0001+$ Others $* 0.0001+$ Unknown * 0.0001) with $\lambda_{1}$ representing the average deaths in Alappuzha for a particular year and vehicle names denote respective cases corresponding to the region. All the vehicle parameters were included in the model as they had a B value not equal to 0 in the model. Similar equations can be framed for the different regions. Dispersion parameter was not considered during the estimation as it does not affect the values predicted. However, year-wise observed and predicted deaths in Kerala as a whole is shown in the Table 7 with their graphical representation in Figure 2. The number of deaths estimated using the model were found to be close to the actual values with no unacceptable variations.

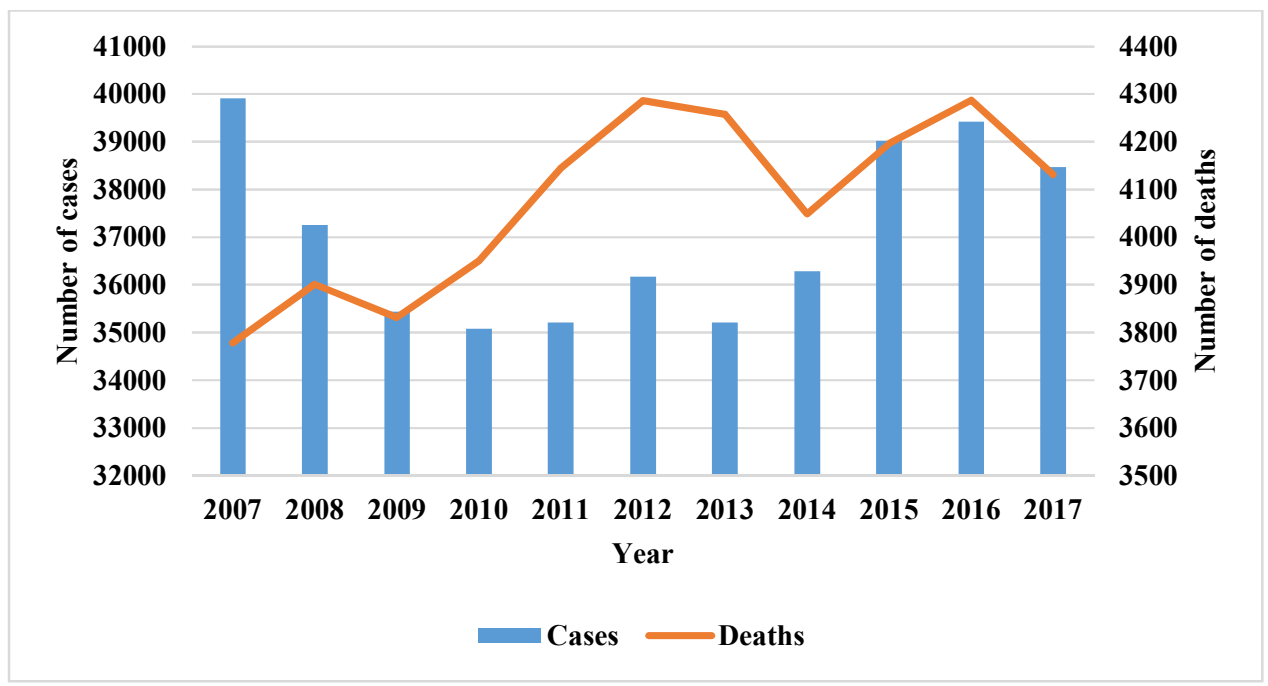

Figure 1: Distribution of cases and deaths from 2007 to 2017

Table 1: Distribution of accident cases due to different vehicles during the years 2007-2017

\begin{tabular}{|c|c|c|c|c|c|c|c|c|c|c|c|c|}
\hline \multirow{2}{*}{ Vehicles } & \multicolumn{11}{|c|}{ Year } & \multirow[t]{2}{*}{ Total } \\
\hline & 2007 & 2008 & 2009 & 2010 & 2011 & 2012 & 2013 & 2014 & 2015 & 2016 & 2017 & \\
\hline Kbus & 1052 & 1208 & 1269 & 1286 & 1368 & 1435 & 1332 & 1200 & 1321 & 1270 & 1252 & 13993 \\
\hline Pbus & 4502 & 4598 & 4362 & 4177 & 4003 & 3819 & 3523 & 3208 & 3293 & 3292 & 2971 & 41748 \\
\hline Lorry & 3010 & 2655 & 2245 & 2248 & 2194 & 2072 & 1967 & 2174 & 2275 & 1956 & 1840 & 24636 \\
\hline Car & 8149 & 9121 & 9406 & 9616 & 9871 & 10365 & 10344 & 10731 & 11641 & 12294 & 12295 & 113833 \\
\hline Mini & 2507 & 2424 & 2183 & 2027 & 1997 & 1967 & 1624 & 1632 & 1673 & 1892 & 1725 & 21651 \\
\hline Jeep & 1585 & 1521 & 1411 & 1298 & 1096 & 1019 & 883 & 897 & 800 & 730 & 618 & 11858 \\
\hline Auto & 6961 & 7598 & 6967 & 6996 & 6920 & 7222 & 6711 & 6477 & 6381 & 5761 & 5651 & 73645 \\
\hline $\begin{array}{c}\text { Two } \\
\text { wheelers }\end{array}$ & 18449 & 23193 & 23161 & 23057 & 23637 & 25445 & 26236 & 28546 & 31614 & 32812 & 33534 & 289684 \\
\hline Others & 720 & 2275 & 1781 & 1827 & 1908 & 1841 & 1861 & 1702 & 1577 & 2249 & 1918 & 19659 \\
\hline Unknown & 1042 & 345 & 324 & 370 & 313 & 252 & 270 & 249 & 210 & 229 & 165 & 3769 \\
\hline \multicolumn{13}{|c|}{ Kbus: KSRTC bus. Pbus: Private bus } \\
\hline
\end{tabular}


Table 2: Eleven years average incidences due to different factors for each district in Kerala

\begin{tabular}{|c|c|c|c|}
\hline \multirow{2}{*}{ Districts } & \multicolumn{3}{|c|}{ Causes } \\
\hline & Rash driving & Drunk and drive & Others \\
\hline Trivandrum city & 1884 & 29 & 66 \\
\hline Trivandrum rural & 2670 & 1 & 101 \\
\hline Kollam & 2883 & 1 & 81 \\
\hline Pathanamthitta & 1436 & 1 & 40 \\
\hline Alappuzha & 3015 & $\mathbf{0}$ & 62 \\
\hline Kottayam & 2581 & 2 & 51 \\
\hline Eranakulam city & 2240 & 8 & 60 \\
\hline Eranakulam rural & 3432 & 1 & 50 \\
\hline Idukki & 1033 & $\mathbf{0}$ & 17 \\
\hline Trissur & 4056 & 2 & 53 \\
\hline Palakkad & 2221 & 1 & 32 \\
\hline Malappuram & 2658 & 1 & 24 \\
\hline Kozhikkode city & 1393 & 9 & 21 \\
\hline Kozhikkode rural & 1566 & $\mathbf{0}$ & 15 \\
\hline Wayanadu & 612 & 1 & 7 \\
\hline Kannur & 1768 & 1 & 20 \\
\hline Kasarakodu & 829 & $\mathbf{0}$ & 8 \\
\hline
\end{tabular}

Table 3: Distribution fit test

\begin{tabular}{|c|c|c|c|c|c|}
\hline \multirow{2}{*}{$\begin{array}{c}\text { Dependent } \\
\text { variable }\end{array}$} & \multirow{2}{*}{ Mean } & \multirow{2}{*}{ Variance } & \multicolumn{2}{|c|}{ Tests for normality (p-value) } & $\begin{array}{c}\text { Test for Poisson distribution fit (p- } \\
\text { value) }\end{array}$ \\
\cline { 4 - 6 } & & & Kolmogorov-Smirnov & Shapiro-Wilk & One-sample Kolmogorov-Smirnov \\
\hline Deaths & $\mathbf{2 4 0}$ & $\mathbf{1 3 9 6 2}$ & $\mathbf{0 . 0 0 0 1}$ & $\mathbf{0 . 0 0 0 1}$ & $\mathbf{0 . 0 0 0 1}$ \\
\hline
\end{tabular}

Table 4: Goodness of fit statistics

\begin{tabular}{|c|c|c|c|c|c|}
\hline Models & Deviance (Value/df) & AIC & BIC & Ancillary parameter & $\begin{array}{c}\text { Omnibus test } \\
(\text { p-value })\end{array}$ \\
\hline Poisson & 1.857 & 1692.32 & 1773.095 & 0 & 0.0001 \\
\hline Negative binomial & 0.915 & 1666.27 & 1747.052 & 0.0045 & 0.0001 \\
\hline \multicolumn{7}{|c|}{ df-degrees of freedom } \\
\hline
\end{tabular}

Table 5: Parameter estimation

\begin{tabular}{|c|c|c|c|c|c|c|c|}
\hline & \multirow[t]{2}{*}{ Parameters } & \multirow[t]{2}{*}{ B } & \multirow[t]{2}{*}{ Std.error } & \multirow{2}{*}{$\begin{array}{l}\text { Wald test } \\
\text { (p-value) }\end{array}$} & \multirow[t]{2}{*}{$\operatorname{Exp}(B)$} & \multicolumn{2}{|c|}{$\begin{array}{l}\text { 95\% confidence interval for Exp } \\
\text { (B) }\end{array}$} \\
\hline & & & & & & Lower bound & Upper bound \\
\hline & Intercept & 4.045 & 0.0535 & 0.0001 & 57.103 & 51.421 & 63.413 \\
\hline \multirow{17}{*}{ Districts } & Alappuzha & 1.318 & 0.1195 & 0.0001 & 3.736 & 2.955 & 4.723 \\
\hline & Ernakulam city & 0.575 & 0.1045 & 0.0001 & 1.777 & 1.448 & 2.181 \\
\hline & Ernakulam rural & 1.179 & 0.1368 & 0.0001 & 3.251 & 2.486 & 4.251 \\
\hline & Idukki & 0.264 & 0.0632 & 0.0001 & 1.303 & 1.151 & 1.474 \\
\hline & Kannur & 0.945 & 0.0802 & 0.0001 & 2.572 & 2.198 & 3.01 \\
\hline & Kasarakodu & 0.428 & 0.0578 & 0.0001 & 1.533 & 1.369 & 1.717 \\
\hline & Kollam & 1.321 & 0.122 & 0.0001 & 3.746 & 2.95 & 4.758 \\
\hline & Kottayam & 0.978 & 0.1062 & 0.0001 & 2.66 & 3.16 & 3.275 \\
\hline & Kozhikkode city & 0.796 & 0.0861 & 0.0001 & 2.217 & 1.873 & 2.825 \\
\hline & Kozhikkode rural & 0.893 & 0.0725 & 0.0001 & 2.443 & 2.12 & 2.816 \\
\hline & Malappuram & 1.282 & 0.12 & 0.0001 & 3.605 & 2.849 & 4.561 \\
\hline & Palakkad & 1.436 & 0.0929 & 0.0001 & 4.205 & 3.504 & 5.045 \\
\hline & Pathanamthitta & 0.591 & 0.0679 & 0.0001 & 1.806 & 1.581 & 2.063 \\
\hline & Trissur & 1.314 & 0.1638 & 0.0001 & 3.72 & 2.699 & 5.129 \\
\hline & Trivandrum city & 0.594 & 0.0876 & 0.0001 & 1.811 & 1.525 & 2.15 \\
\hline & Trivandrum rural & 1.174 & 0.1201 & 0.0001 & 3.236 & 2.558 & 4.095 \\
\hline & Wayanadu & $\mathbf{0}$ & & & 1 & & \\
\hline \multirow{8}{*}{ Vehicles } & Kbus & 0.001 & 0.0005 & 0.008 & 1.001 & 1.000 & 1.002 \\
\hline & Pbus & 0.0001 & 0.0003 & 0.933 & 1.0001 & 0.999 & 1.001 \\
\hline & Lorry & 0.0001 & 0.0003 & 0.212 & 1.0001 & 1.000 & 1.001 \\
\hline & Mini & 0.0001 & 0.0003 & 0.51 & 1.0001 & 0.999 & 1.000 \\
\hline & Auto & 0.0001 & 0.0002 & 0.345 & 1.0001 & 1.000 & 1.001 \\
\hline & Cars\&Two-wheelers & 0.0001 & 0.00002 & 0.000 & 1.0001 & 1.000 & 1.0001 \\
\hline & Others & 0.0001 & 0.0002 & 0.396 & 1.0001 & 0.999 & 1.000 \\
\hline & Unknown & 0.0001 & 0.0004 & 0.542 & 1.0001 & 0.999 & 1.001 \\
\hline \multicolumn{8}{|c|}{ Kbus: KSRTC bus, Pbus: Private bus } \\
\hline
\end{tabular}


Table 6: Estimated marginal means

\begin{tabular}{|c|c|c|c|}
\hline \multirow{2}{*}{ Districts } & \multirow{2}{*}{ Mean deaths } & \multicolumn{2}{|c|}{ 95\% Wald Confidence Interval } \\
\hline & & Lower & Upper \\
\hline Alappuzha & 320 & 288 & 357 \\
\hline Ernakulam city & 152 & 138 & 169 \\
\hline Ernakulam rural & 279 & 246 & 316 \\
\hline Idukki & 112 & 98 & 127 \\
\hline Kannur & 220 & 204 & 239 \\
\hline Kasarakodu & 131 & 114 & 151 \\
\hline Kollam & 321 & 288 & 358 \\
\hline Kottayam & 228 & 212 & 245 \\
\hline Kozhikkode city & 190 & 165 & 218 \\
\hline Kozhikkode rural & 209 & 191 & 229 \\
\hline Malappuram & 309 & 278 & 343 \\
\hline Palakkad & 360 & 335 & 388 \\
\hline Pathanamthitta & 155 & 141 & 170 \\
\hline Trissur & 319 & 267 & 381 \\
\hline Trivandrum city & 155 & 141 & 171 \\
\hline Trivandrum rural & 277 & 244 & 315 \\
\hline Wayanadu & 86 & 73 & 101 \\
\hline
\end{tabular}

Table 7: Year-wise prediction of Kerala deaths

\begin{tabular}{|c|c|c|}
\hline Year & Observed & Predicted \\
\hline 2007 & 3778 & 3850 \\
\hline 2008 & 3901 & 3949 \\
\hline 2009 & 3831 & 3943 \\
\hline 2010 & 3950 & 3977 \\
\hline 2011 & 4145 & 4041 \\
\hline 2012 & 4286 & 4132 \\
\hline 2013 & 4258 & 4090 \\
\hline 2014 & 4049 & 4126 \\
\hline 2015 & 4196 & 4291 \\
\hline 2016 & 4287 & 4187 \\
\hline 2017 & 4131 & 4223 \\
\hline
\end{tabular}

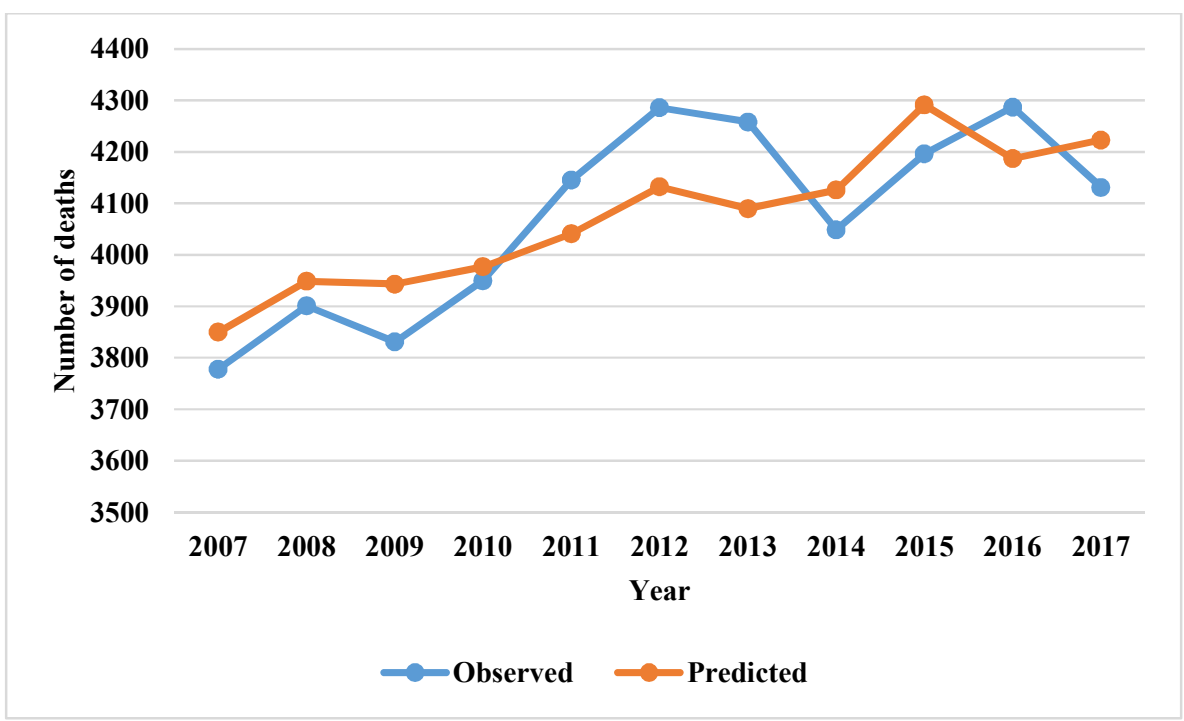

Figure 2: Comparison of observed and predicted deaths over a span of 11 years

\section{DISCUSSION}

Since 2013, Ernakulam followed by Trivandrum have reported the highest vehicle population, with the least recordings in Wayanadu. Every year, personal vehicles were found to report a faster growth rate in the entire state with higher risks due to multivehicle interactions 
and insufficient space [4]. Districts of Trivandrum, Ernakulam, and Trissur have high health care facilities, where urbanization, industrialization, and population growth play a supreme role in the provision of health care services [14]. Emergency response times are a crucial factor deciding the risk of fatality during a road accident. Many of the road collision victims die because the rescue teams arrive late at the location. It is quite obvious that urban areas records lower deaths as more number of hospitals are located at a lesser distance and transfer of victims is possible in a shorter period. As per the data, since the accident cases also appeared higher in number in rural regions, improper road maintenance can be thought of as the reason. Kannur, Kottayam, Kozhikode and Alappuzha stand second in the health care facility order with tourism being predominant in Alappuzha. Such districts do have good accessibility and connectivity to the transport. In the border districts of Pathanamthitta, Idukki, Kasarakodu, Palakkad and Wayanadu comparatively less developed health care facilities are observed. These districts are situated in the Kerala highland zone. Such districts are characterized by low density, composed of more SC / ST and rural communities. More than $35 \%$ of the geographic areas of Pathanamthitta (59\%), Idukki (47\%) and Wayanadu (37\%) are covered by forests in the highland regions. There are also not very busy road networks and most importantly, vehicles are not permitted to cross this area during the night by passage and forest area, it is limited there, this is why it plays a very important role in lower accident rates and its deaths. Thus rise in particular vehicle type either due to an individual's desire or due to the regional restrictions can be considered as the main cause behind the increase in specific automobile cases $[\mathbf{1 6}, \mathbf{1 8}]$.

Over the years, an individual's desire or regional restrictions can be considered as the main cause behind the huge rise in specific automobiles and their movements, such as two wheelers and cars in Kerala, thereby exposing them more to the accidents as compared to the remaining vehicles. However, it is important to note that, vehicles like bus expose large number of passengers while when two-wheelers and cars are considered, lesser number are exposed to accidents. Therefore, lower incidences of Kbus with more deaths and increased car and two-wheeler cases with lesser deaths are equally dreadful. As a result, since rash driving is a major reason behind the accidents, as obtained from our data, proper advisory methods should be adopted by the respective authorities to bring about changes in the driver's behaviour. Although other factors such as road structures, 
overloading of passengers, effects of bad weather, defect in the automobiles, and fault of the pedestrians may be minor contributors, concentrating on their control and preventive measures such as education in road safety for different types of road users, rectification of road design, shortcomings in the inclusion of road safety issues of road construction planning and operating stages are the key facts to be taken up which can be very useful in reducing accident severity. In addition to this, more attention should be drawn towards the maintenance of accidental reports as in our study there were presence of some cases due to unknown vehicles and a knowledge about them could have altered the results. Also, the results were obtained considering equal exposure of the population towards accidents in each district [4].

\section{CONCLUSION}

For a developing state like Kerala, giving importance to even minute factors that brings down the population density is very much necessary. Road accident is one such disaster that, not only kills people but pushes many of them into grievous suffering as a consequence of the damages or loss faced by the society. The affected regions will have to confront with greater economy and environmental hardships. In our study, the application of Negative Binomial Regression Model served useful to a great extent in determining the high risk regions and vehicles related to the road accidents in Kerala. Although rash driving appears to be the most prominent reasons, attention should also be drawn towards the other causes by the management. In addition to this we as individuals should take responsibility to prevent selfdeprivation and deprivation to the environment in which we are living, by adopting precautionary measures, most important being, following traffic rules and regulations.

\section{Conflict of interest}

The authors do not have any conflict of interest with other entities or researchers.

\section{Acknowledgement}

The authors sincerely thank Head of the Department, Department of Water and Health, JSS Academy of Higher Education and Research, Mysore, for having granted the use of SPSS software for performing the statistical analysis.

\section{REFERENCES}

[1]Ruikar M. National statistics of road traffic accidents in India. Journal of Orthopedics, Traumatology and Rehabilitation. 2013; 6(1): 1-6.

[2]Singh S. K. Road traffic accidents in India: issues and challenges. Transportation research procedia. 2017; 25: 4712-4723.

[3]Vigneshkumar C, Arichandran R. Fatal road accidents in Kerala (India): 
characteristics, causes and remedial measures. International Journal of Research. 2015; 4(4): 4-5.

[4]ENVIS Centre: Kerala, State of Environment and Related Issues.http://www.kerenvis.nic.in/Datab ase/INFRASTRUCTURE_812.aspx

[5]Muller M. Generalized Linear Models. 2004. DOI: $10.1007 / 978-3-642-21551-$ $3 \_24$.

[6]Famoye F, Wulu JT, Singh KP. On the generalized Poisson regression model with an application to accident data. Journal of data science. 2004; 2(2004): 287-95.

[7]Kerala.

https://en.wikipedia.org/wiki/Keral

[8]Joseph M Hilbe, Modelling count data, http://dx.doi.org/10.1017/CBO9781 139236065.003.

[9]Abdel-Aty MA, Radwan AE. Modeling traffic accident occurrence and involvement. Accident Analysis \& Prevention. 2000; 32(5): 633-42.

[10]Yang S, Berdine G. Poisson Regression. The Southwest Respiratory and Critical Care Chronicles. 2015; 3(9): 61-64.

[11]Joseph M Hilbe, Negative Binomial Regression (2 ${ }^{\text {nd }}$ Edition, 2011).

[12] Oyedepo JO, Etu JE. Poisson and Negative Binomial Regression Models Application to Model the Factors of Car Ownership in Akure, South West,
Nigeria. Journal of Applied Science \& Process Engineering. 2016 Sep 30; 3(2): $72-82$.

[13] Ye X, Wang K, Zou Y, Lord D. A semi-nonparametric Poisson regression model for analyzing motor vehicle crash data. PloS one. 2018; 13(5).

[14] Wald test.

https://www.statisticshowto.com/waldtest/

[15] Razali MS, Zamzuri ZH. Modeling motorcycle road accidents with traffic offenses at several potential locations using negative binomial regression model in Malaysia. International Journal of Applied Mathematics and Statistics. 2016; 54(3): 104-114.

[16] Koley S, Srivastava S, Ghosal P. Correlating Fatality Rate to Road Accidents in India: A Case Study Using Big Data. In2018 IEEE International Symposium on Smart Electronic Systems (iSES) (Formerly iNiS) 2018 (pp.171- 176). IEEE.

[17] Nair MN, Thangamani V. An Analysis of Spatialy Explicit Scenario of Road Traffic Accidents in Kerala Using GIS. International Journal of Science and Research. 2015: 4(10): 356-359.

[18] Spatial distribution of health care services and facilities in Kerala state. http://shodhganga.inflibnet.ac.in/jspui/ bitstream/10603/133267/9/09_chapter \%203.pdf. 